\title{
Docking and Quantum Mechanics-Guided CoMFA Analysis of b-RAF Inhibitors
}

\author{
M. Muddassar, F. A. Pasha, Kyung Ho Yoo, So Ha Lee, and Seung Joo Cho $0^{+\neq}$ \\ Korea Institute of Science and Technologv, P.O. Box 131, Cheongrvang, Seoul 130-650, Korea \\ -Research Center for Resistant Cells, Chosun Chiversit, Gu'angin 501-759, Korea. ${ }^{*}$-mail: chosiâchosun ac.kr \\ -College of Medicine, Chosun Universin, Gwangiu $501-759$. Korea \\ Received April 23, 2008
}

\begin{abstract}
Pyrazine derivatives bind to b-RAF receptor which is inportant in cancer therapy. The ligand-receptor interactions have been studied by comparative molecular field analysis (COMFA) and molecular docking methods. Applying conventional ligand-based alignument schemes for the whole set was not successful. However, QM and DFT results suggested that some ligands have electrostatic interaction while others have steric interactions. On the basis of these results. we divided the dataset into two subsets. Electrostatic effect was found to be important in one set while steric effect for the other. Best docking modes were obtained for each subset based on the available crystal structure. These receptor-guided CoMFA models propose an interesting possibility which is difficult to obtain otherwise. i.e. in one binding mode the electrostatic interaction plays a key role for one subset $\left(\hat{q}^{2}=0.46, \mathrm{r}^{\hat{2}}=0.98\right)$. while in another binding mode steric effect is important with another subset $\left(\mathrm{q}^{2}=0.43, \mathrm{r}^{2}=0.74\right)$.
\end{abstract}

Key Words : QSAR. CoMFA. DFT. Docking. b-RAF

\section{Introduction}

b-RAF belongs to the RAF family of serine/threonine kinases. ${ }^{1}$ It involves in signal transduction pathway that implicates in oncogenesis, cell proliferation, survival, ${ }^{2}$ and angiogenesis in various cancer models. b-RAF is the component of the RAF-MAPK kinase-ERK (RAF-MEK-ERK) pathway that is activated through binding to RAS in its GTPbound state. Once activated. RAF kinase can phosphory late MEK, which in turn phosphorylates and activates ERKs. ${ }^{3}$ Recently it has been shown that b-RAF is mutationally activated in two-thirds of all human melanomas ${ }^{4}$ as well as in a smaller percentage of other human cancers. 50 Interestingly, nearly $90 \%$ of the oncogenic mutations found in bRAF are accounted for by a single amino acid change of glutamate for valine at residue 599 , which renders the kinase constitutively active by destabilizing the inactive confirmation ${ }^{7.8}$ However there are some mutants which stimulate ERK pathway by stabilizing the active conformation. ${ }^{9}$ Different inhibitors have been designed to block both confirmations of b-RAF effectively. ${ }^{1{ }^{15}-12}$ There are also some other classes of b-RAF inhibitors like benzylidine indolinones, ${ }^{13}$ amides ${ }^{1+}$ and triaryl amidazoles which have been shown their activities against the RAF kinases. Recently the 3DQSAR of urea derivatives was performed with their b-RAF inhibitory activities. ${ }^{15}$ The disubstituted pyrazines were also identified as novel b-RAF inhibitors. ${ }^{6}$ The interactions between pyrazine derivatives and b-RAF receptor are not clearly known without any co-crystal structure. In this study. DFT calculations and molecular docking experiments were performed to identify the plausible binding modes. The binding affinities were related to structural features by using DFT based QSAR ${ }^{16.17}$ and 3D-QSAR. ${ }^{18,19}$

\section{Material and Method}

The basic structure of disubstituted pyrazine is shown in Figure 1. A series of 40 compounds of very similar structures with observed binding affinities were taken from literature. ${ }^{6}$

The structures of all substituents are presented in Table 1 In the absence of X-ray structure to identify an active template the most active molecule (ligand 24) was drawn by sybyl 7.3 and the geometry was optimized with Tripos force field. ${ }^{3 i}$ Gasteiger-Hückel charges with a distance-dependent dielectric constant. The convergence criterion was $0.01 \mathrm{kcal} /$ mol. Two different methods were used to identify the global energy minimum of the most active molecule within framework of ligand based method and used as geometrical scheme 1 and 2 while the receptor based method. the molecular docking used in geometrical scheme-3.

CoMFA. Lennard-Jones and Coulomb potentials based CoMFA analysis has been performed and the steric as well as electrostatic energies were calculated by using $\mathrm{sp}^{3}$ carbon probe atom with van der Waals radius of $1.52 \AA$ and $a+1$ charge. The energies were truncated to $\pm 30 \mathrm{kcal} \mathrm{mol}^{-1}$ and the electrostatic contributions were ignored at lattice interactions with maximum steric interactions. The CoMFA

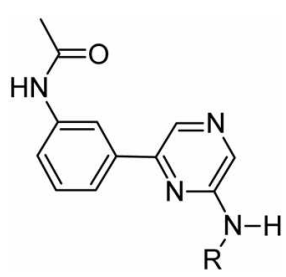

Figure 1. The common structure of b-RAF inhibitors. 
Table 1. The molecular structure and observed b-RAF inhibitory activity
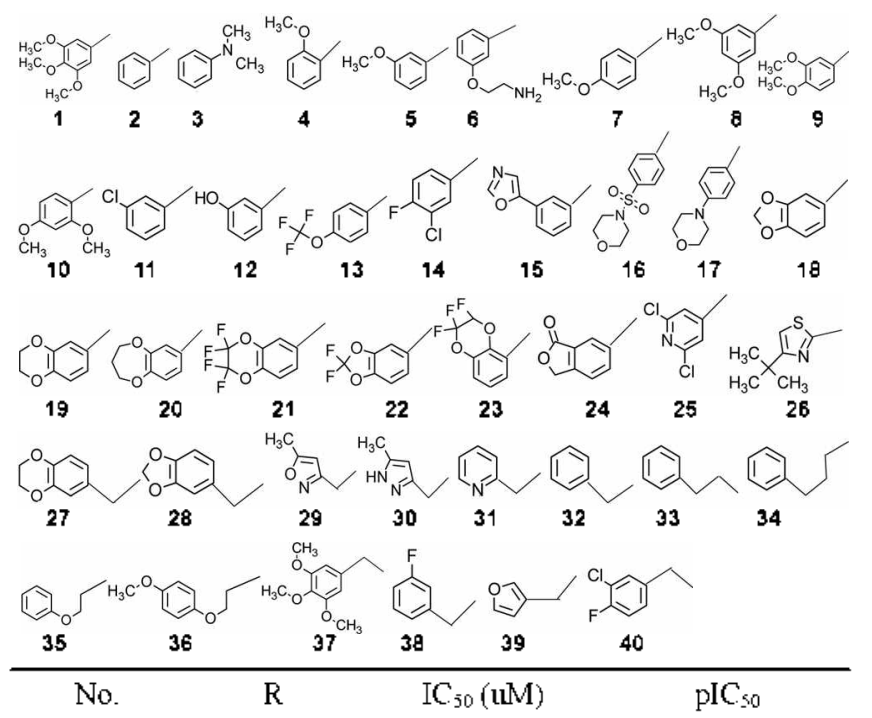

\begin{tabular}{|c|c|c|c|}
\hline No. & $\mathrm{R}$ & $\mathrm{IC}_{50}(\mathrm{uM})$ & $\mathrm{pIC}_{50}$ \\
\hline 1 & l & 3.5 & -0.54 \\
\hline 2 & 2 & 7.9 & -0.90 \\
\hline 3 & 3 & 100 & -2.00 \\
\hline 4 & 4 & 74 & -1.87 \\
\hline 5 & 5 & 4.8 & -0.68 \\
\hline 6 & 6 & 3.8 & -0.58 \\
\hline 7 & 7 & 26. & -1.41 \\
\hline 8 & 8 & 2.7 & -0.43 \\
\hline 9 & 9 & 1.3 & -0.11 \\
\hline 10 & 10 & 21 & -1.32 \\
\hline 11 & 11 & 8.8 & -0.94 \\
\hline 12 & 12 & 14. & -1.15 \\
\hline 13 & 13 & 84. & -1.92 \\
\hline 14 & 14 & 100 & -2.00 \\
\hline 15 & 15 & 0.79 & 0.10 \\
\hline 16 & 16 & 8.8 & -0.94 \\
\hline 17 & 17 & 10. & -1.00 \\
\hline 18 & 18 & 10. & -1.00 \\
\hline 19 & 19 & 5.4 & -0.73 \\
\hline 20 & 20 & 4.5 & -0.65 \\
\hline 21 & 21 & 39. & -1.59 \\
\hline 22 & 22 & 37. & -1.57 \\
\hline 23 & 23 & 100. & -2.00 \\
\hline 24 & 24 & 0.74 & 0.13 \\
\hline 25 & 25 & 0.95 & 0.02 \\
\hline 26 & 26 & 20. & -1.30 \\
\hline 27 & 27 & 34. & -1.53 \\
\hline 28 & 28 & 3.8 & -0.58 \\
\hline 29 & 29 & 4.2 & -0.62 \\
\hline 30 & 30 & 14. & -1.15 \\
\hline 31 & 31 & 100 & -2.00 \\
\hline 32 & 32 & 18 & -1.25 \\
\hline 33 & 33 & 45 & -1.65 \\
\hline 34 & 34 & 100 & -2.00 \\
\hline 35 & 35 & 65 & -1.81 \\
\hline 36 & 36 & 58. & -1.76 \\
\hline 37 & 37 & 100 & -2.00 \\
\hline 38 & 38 & 8. & -0.90 \\
\hline 39 & 39 & 33. & -1.52 \\
\hline 40 & 40 & 99. & -1.99 \\
\hline
\end{tabular}

Table 2. The values of observed and predicted activities of subset "A" by quantum chemical descriptors

\begin{tabular}{rcrrrr}
\hline No & $\varepsilon_{\text {HoMo }}$ & Log P & plC50 & \multicolumn{1}{c}{ PA } & Residual \\
\hline 1 & -5.496824 & 1.547 & -0.55 & -0.38 & 0.17 \\
2 & -5.496824 & 2.305 & -0.89 & -1.07 & -0.18 \\
4 & -5.360764 & 2.053 & -1.86 & -1.12 & 0.75 \\
5 & -5.524036 & 2.053 & -0.68 & -0.79 & -0.11 \\
6 & -5.469612 & 1.262 & -0.57 & -0.18 & 0.39 \\
7 & -5.306340 & 2.000 & -1.41 & 0.05 & 1.46 \\
8 & -5.578460 & 1.000 & -0.43 & 0.80 & 1.23 \\
9 & -5.279128 & 1.800 & -0.11 & -1.05 & -0.94 \\
10 & -5.143068 & 1.800 & -1.32 & -1.32 & 0.00 \\
11 & -5.660096 & 2.823 & -0.94 & -1.22 & -0.27 \\
12 & -5.469612 & 2.021 & -1.15 & -0.87 & 0.28 \\
13 & -5.632884 & 3.798 & -1.92 & -2.16 & -0.24 \\
14 & -5.687308 & 2.963 & -2.00 & -1.29 & 0.71 \\
15 & -5.578460 & 1.000 & 0.10 & 0.64 & 0.53 \\
18 & -5.279128 & 1.640 & -1.00 & -0.90 & 0.10 \\
19 & -5.360764 & 1.622 & -0.73 & -0.72 & 0.01 \\
20 & -5.415188 & 1.674 & -0.65 & -0.66 & -0.01 \\
21 & -5.660096 & 3.528 & -1.59 & -1.86 & -0.27 \\
22 & -5.578460 & 2.000 & -1.56 & 1.00 & 2.56 \\
23 & -5.714520 & 3.000 & -2.00 & 0.53 & 2.53 \\
\hline
\end{tabular}

Compounds 16 and 17 are not included in data set. EHomo = Eigen value of HOMO, Log $\mathrm{P}=$ Octanol water partition function, pIC50 = observed $\mathrm{B} R \mathrm{RA}$ inhibitory activity, $\mathrm{PA}=$ predicted acticity.

models were generated by standard method in SYBYL. The Partial least square analy sis (PLS) performed and leave-oneout method was used to calculate $\mathrm{q}^{2}$ values of each set Column filtering of 2.0 was applied to speed up the calculation and reduce the noise.

DFT study. The all molecules were fully optimized with DFT method using b3lyp functional with $6-31 \mathrm{~g}^{* *}$ basis set in gas phase. Self-consistent reaction field (SCRF) calculations and population analysis were carried out by natural population analy'sis (NPA) scheme by Gaussian-03 software. The important molecular properties like energies of frontier orbital. $\log \mathrm{P}$ values, solvent assessable surface (SAS). molar refractivity (MR), and molecular weight (MW) etc were calculated and correlated with binding affinities by using multiple linear regression analysis (MLR).

\section{Results}

Comparative molecular field analysis (CoMFA) ${ }^{21}$ is a tool to establish the QSAR. First of all, the most potent ligand 24 was drawn and minimized with Tripose forcefield. After the random and systematic search based confonmational analysis. the global energy minimum was used as template for geometrical scheme-1 and -2 respectively:

Geometrical scheme-1. The randon search based minimum energy conformer of ligand 24 was taken and modified for further ligands by fixing the common moiety. All molecules were aligned using conmon sub structure of these molecules. These structures were used for CoMFA and 
three different models were developed using different sets of parameters. The combined use of both steric and electrostatic field yielded non cross validated correlation coefficient $\left(\hat{r^{2}}=0.97\right)$ and cross validated correlation coefficient $\left(\mathrm{q}^{2}=0.32\right.$. Table 6$)$. Thus the overall results from "Geometrical scheme-1" are not satisfactory owing to their low internal predictive power.

Geometrical scheme-2. The systematic search based minimum energy conformer of ligand 24 was taken and modified for further ligands by fixing the common moiety. All procedure was similar as in case of "geometrical scheme- 1 ". The combined use of steric and electrostatic field gave reasonable correlation $\left(\hat{r}^{\hat{}}=0.99\right)$ but the internal predictivity of this model $\left(\hat{q}^{2}=0.25\right)$ was poor as shown in Table 6. This low predictive power of the models derived from both "ligand-based geometrical schemes" night inty heterogeneity of our dataset. To gain more insight regarding binding mode and interactions of inhibitors we used DFT. based QSAR.

DFT and quantum chemical analysis. In this study DFT based descriptors like frontier orbital energies. global hardness. ${ }^{20}$ softness, ${ }^{23}$ electronegativity, ${ }^{23}$ chemical potential. electrophilicity index. ${ }^{2-}$ total energy. frontier orbital densities, molar refractivity, solvent assessable surface area and molecular weight were calculated. Multiple linear regression analyses were used to develop the QSAR model but initially no signifant results were found. After careful considerations. the whole dataset was divided into two subsets mostly based on the structural difference. The subset $A$ and $B$ with their structural similarities are reported in Table 2 and 3 . The MLR analysis gave a significant model PA for subset " $A$ " having value of $\hat{r}=0.68$ and $\hat{r}_{\mathrm{v} w}=0.60$. The regression

Table 3. The values of observed and predicted activities of subset "B" by Steric descriptors

\begin{tabular}{rrrrrrrr}
\hline No & MW & SAS & \multicolumn{1}{c}{ MR } & $I$ & PIC 50 & PA & Resi. \\
\hline 24 & 360.371 & 166.18 & 98.47 & 0 & 0.13 & -0.21 & -0.34 \\
25 & 374.229 & 167.62 & 97.97 & 1 & 0.02 & -0.07 & -0.09 \\
26 & 367.468 & 163.72 & 103.34 & 1 & -1.30 & -1.37 & -0.07 \\
27 & 376.414 & 174.24 & 105.67 & 0 & -1.53 & -1.20 & 0.33 \\
28 & 362.387 & 169.13 & 100.33 & 0 & -0.58 & -0.63 & -0.05 \\
29 & 323.354 & 158.15 & 89.87 & 1 & -0.62 & -0.76 & -0.14 \\
30 & 322.369 & 159.15 & 92.12 & 1 & -1.14 & -1.33 & -0.18 \\
31 & 319.365 & 155.79 & 92.18 & 1 & -2.00 & -1.34 & 0.66 \\
32 & 318.377 & 157.08 & 94.71 & 0 & -1.25 & -1.32 & -0.07 \\
33 & 332.404 & 162.70 & 99.47 & 0 & -1.65 & -1.80 & -0.15 \\
34 & 346.431 & 171.32 & 104.07 & 0 & -2.00 & -2.39 & -0.39 \\
35 & 348.404 & 170.27 & 100.65 & 0 & -1.81 & -1.53 & 0.28 \\
36 & 378.430 & 181.92 & 107.11 & 0 & -1.76 & -1.77 & -0.01 \\
37 & 408.456 & 190.25 & 114.10 & 0 & -2.00 & -1.95 & 0.05 \\
38 & 336.368 & 160.45 & 94.93 & 0 & -0.90 & -0.53 & 0.37 \\
39 & 308.339 & 150.39 & 87.29 & 1 & -1.51 & -0.68 & -0.87 \\
404 & 370.813 & 170.99 & 99.73 & 0 & -1.99 & -0.13 & -1.86 \\
$3^{4}$ & 333.392 & 162.16 & 91.29 & 0 & -2.00 & -0.03 & -1.97 \\
\hline
\end{tabular}

"data point not used in final model. $\mathrm{MW}=$ molecular weight. SAS = solvent assessable surface area, $\mathrm{MR}=$ molar refractivity, $I=$ indicator parameter. PIC50 = obsered B RAF inhibitory activity equation (1) has been developed for this model and the predicted activities are reported in Table 2 .

$$
\begin{aligned}
& \mathrm{PA}_{\mathrm{A}}=-2.00801 \times \mathrm{HOMO}-0.911734 \times \log \mathrm{P}-10.008 \\
& \mathrm{r}_{\mathrm{CY}}=0.60 \mathrm{r}^{2}=0.68
\end{aligned}
$$

This model is based on HOMO energy and $\log P$ which indicates the dominance of lipophilic and electrostatic interactions.

Similarly MLR analysis gave a significant model $\mathrm{PA}_{\mathrm{B}}$ for set $B$ with a values of correlation coefficient $r^{2}=0.84$ and cross validation coefficient $r_{c r}^{2}=0.55$. The regression equation (2) has been developed and the predicted activities are reported in Table 3 .

$$
\begin{aligned}
\mathrm{PA}_{\mathrm{B}}= & 0.0554224 \times \mathrm{MW}-0.0486759 \times \mathrm{SAS}-0.206747 \\
& \times \mathrm{MR}-0.662021 \times \mathrm{I}+8.26097 \\
\mathrm{r}^{2} \mathrm{CV}= & 0.55 \mathrm{r}^{2}=0.84
\end{aligned}
$$

This model is based on molecular weight (MW), solvent accessible surface area (SAS) and molar refractivity (MR) which shows the dominance of steric bulk interactions for subset B. An indicator parameter I was used for and all molecules having hexagonal ring at $R$ with $I=l$ while rest of the molecules were allotted. $I=0$. The DFT based study reveals the complexity of interactions between ligand series and target protein. This significant fundings lead to develop a receptor-based QSAR.

Geometrical scheme-3. Recently a crystal structure of very similar ligand was reported and can be obtained from protein data bank (PDB IUWH). The molecular docking employed for receptor based QSAR. The PDB file IUWH taken and molecular docking of most active ligand (Com-

Table 4. The values of observed and predicted activities of subset A by electrostatic field effect based CoMFA model

\begin{tabular}{crrr}
\hline No. & pIC50 & PA & Resi \\
\hline 1 & -0.54 & -0.49 & 0.05 \\
2 & -0.80 & -0.99 & -0.19 \\
4 & -1.87 & -1.53 & 0.34 \\
5 & -0.68 & -0.64 & 0.05 \\
6 & -0.57 & -0.58 & -0.01 \\
7 & -1.41 & -1.24 & 0.17 \\
8 & -0.43 & -0.43 & 0.00 \\
9 & -0.11 & -0.24 & -0.13 \\
10 & -1.32 & -1.41 & -0.09 \\
11 & -0.94 & -0.82 & 0.12 \\
12 & -1.14 & -1.16 & -0.02 \\
13 & -1.92 & -1.78 & 0.14 \\
14 & -2.00 & -2.09 & -0.09 \\
15 & 0.10 & 0.10 & -0.01 \\
16 & -0.94 & 2.00 & 2.94 \\
$17^{\circ}$ & -1.00 & 2.30 & 3.30 \\
18 & -1.00 & -0.75 & 0.25 \\
19 & -0.73 & -0.74 & -0.02 \\
20 & -0.65 & -0.62 & 0.03 \\
21 & -1.59 & -1.68 & -0.09 \\
22 & -1.56 & -1.56 & 0.00 \\
23 & -2.00 & -1.96 & 0.04 \\
\hline
\end{tabular}

data not used in the training set 
Table 5 . The values of observed and predicted activities of subset " $B$ " by steric field eftect based CoMFA model

\begin{tabular}{crrr}
\hline No. & PIC50 & PA & Resi. \\
\hline 3 & -2.00 & -1.57 & -0.43 \\
24 & 0.13 & 0.03 & 0.10 \\
25 & 0.02 & -0.11 & 0.13 \\
26 & -1.30 & -1.17 & -0.13 \\
27 & -1.53 & -1.35 & -0.19 \\
28 & -0.58 & -1.15 & 0.57 \\
29 & -0.62 & -0.99 & 0.37 \\
30 & -1.14 & -1.09 & -0.05 \\
31 & -2.00 & -1.37 & -0.63 \\
32 & -1.25 & -1.33 & 0.08 \\
$33^{\circ}$ & -1.63 & -0.47 & -1.16 \\
34 & -2.00 & -1.97 & -0.03 \\
35 & -1.81 & -1.99 & 0.18 \\
36 & -1.76 & -2.15 & 0.39 \\
37 & -2.00 & -2.13 & 0.13 \\
38 & -0.90 & -1.38 & 0.48 \\
39 & -1.51 & -1.04 & -0.47 \\
40 & -1.99 & -1.48 & -0.52 \\
\hline
\end{tabular}

"data point not used in equation

pound-30) were performed to obtain the plausible binding pose.

Molecular docking. The most active molecule (compound 24) was docked into receptor site by using FlexX. The crystal structure (luwh) was used. The ligand with all water molecules was deleted and Gasteiger-Hûckel charges were assigned. The ligand based active site was defuned within the area of $6.5 \bar{A}$ and compound 24 was docked into the b-RAF active site using FlexX with default setting and 100 possible conformers were generated. The best fitted two binding modes " $\mathrm{A}$ " and " $\mathrm{B}$ " were identified as shown in Figure 2 and 3 . The criterion of best fitted modes was based on hydrogen bonding. comparison with the ligand already in binding pocket of b-RAF best $\mathrm{C}$ Score and low RMSD among the 100 confirmations.

The best fitted two conformers A (mode-89) and B (mode4) of ligand 24 were taken as template as shown in Figure 4 and 5. They have similar structure but the direction of furan moiety is different. It was found that subset A prefers

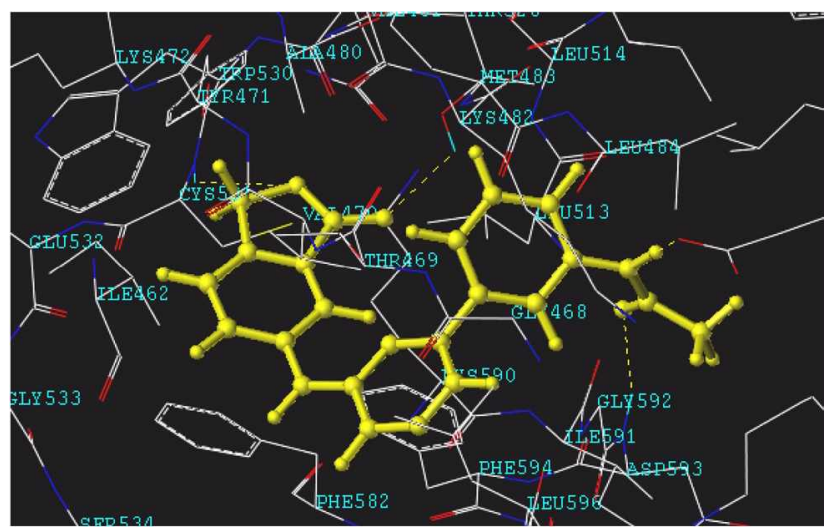

Figure 2. The Docked mode "A" of ligand 24

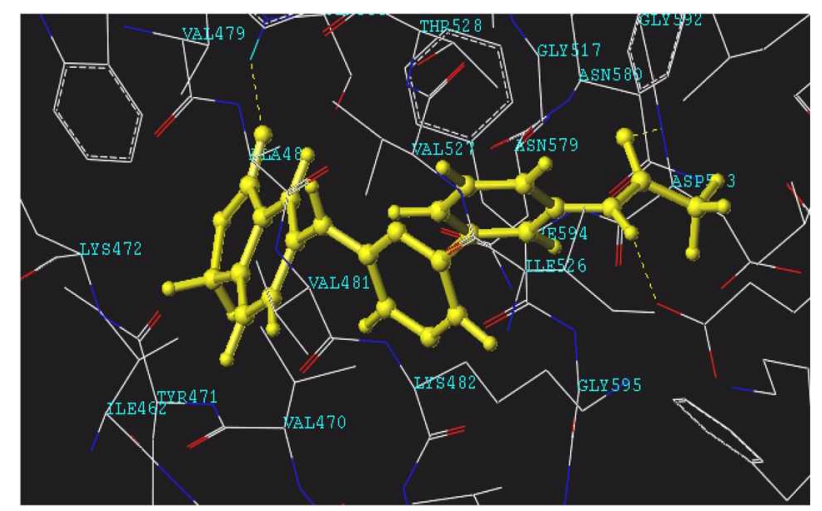

Figure 3. The Docked mode " $\mathrm{B}$ " of ligand 24.

binding mode $A$ while subset $B$ likes binding mode $B$. This result might come from the structural difference of both sets. i.e., most of the molecules from subset $\mathrm{B}$ are longer than those from subset $\mathrm{A}$.

Subset A. The Mode " $\mathrm{A}$ " of ligand 24 was used as template and modified for further ligands of subset " $A$ " by fixing common moiety: All structures were aligned. using common substructure of the molecules. as shown in Figure 6 and this alignment was used for CoMFA.

CoMFA of Subset A: Three different CoMFA models were developed by steric and electrostatic descriptors. The model based on electrostatic field parameter showed a strong correlation and moderate predictivity $\left(\mathrm{q}^{2}=0.46, \mathrm{r}^{2}=\right.$

Table 6. The regression summary of difterent CoMFA models

\begin{tabular}{|c|c|c|c|c|c|c|c|c|c|}
\hline Geometry & $\mathrm{N}$ & Field & $q^{2}$ & n & $r^{2}$ & SFE & $\mathrm{F}$ & $r_{b s}$ & $\mathrm{SD}$ \\
\hline \multirow[t]{3}{*}{ SS } & 40) & $E$ & 0.09 & - & - & - & - & - & - \\
\hline & 40 & $\mathrm{~S}$ & 0.13 & - & - & - & $=$ & - & - \\
\hline & 40 & $\mathrm{~S} / \mathrm{F}$. & 0.25 & 8 & 0.99 & 0.073 & 309 & - & - \\
\hline \multirow[t]{3}{*}{ RS } & 40 & $S$ & 0.11 & - & - & 0.072 & & - & - \\
\hline & 40 & $\mathrm{~F}$ & 0.26 & 5 & 0.91 & 0.204 & 148.9 & - & - \\
\hline & 40 & $\mathrm{~S} / \mathrm{F}$. & 0.32 & 7 & 0.97 & 0.12 & - & - & - \\
\hline DG/Mode-A & 21 & $\mathrm{~F}$ & 0.46 & 8 & 0.98 & 0.117 & 72.59 & 0.99 & 0.002 \\
\hline DG/Mode-B & 18 & $S$ & 0.43 & 2 & 0.74 & 0.384 & 20.04 & 0.80 & 0.058 \\
\hline
\end{tabular}

$\mathrm{SS}=$ systematic search. RS = random search. DG $=$ dock geometry $\mathrm{N}=$ number of compounds. $n=$ no of components in PLS. SEE $=$ standard error of estimation, $\mathrm{q} 2$ = cross falidated correlation coeflicient, $\mathrm{r} 2=$ correlation coefficient, $\mathrm{r} 2 \mathrm{bs}=$ conrelation coeflicient boot strapping. $\mathrm{E}=$ electrostatic. $\mathrm{S}=$ steric 


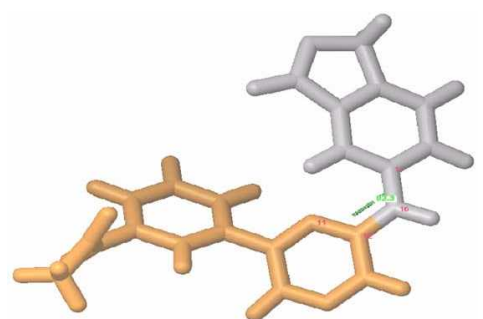

Figure 4. Mode "A" (contormer-89)

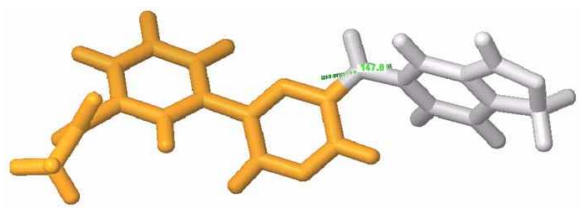

Figure 5. Mode " $\mathrm{B}$ " (conformer-4).

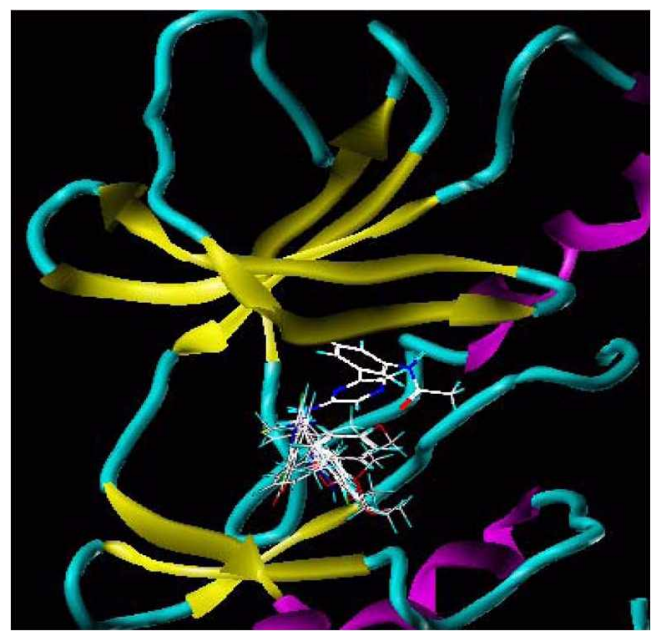

Figure 6. superposition of all molecules of subset A bound to b-Raf.

0.98 ). This funding supports the DFT result and shows the dominance of electrostatic interaction among the ligand of subset "A". CoMFA contour map of subset " $\mathrm{A}$ " is shown in Figure 7.

A red contour appear around carbonyl group of benzofuran moiety indicates that an electronegative group is desirable over this place. In case of docked mode-A this position corresponds to residue THR 528 of receptor protein and carbonyl oxygen holds a key hydrogen bond with hy'droxyl group of THR528. As clear from Figure 7, a highly' negative group will facilitate the bonding which might be helpful to improve the activity. A blue contour at benzene ring adjacent to the furan as well as around $\mathrm{NH}$ group indicates that an electropositive group is desirable for this region. This region of inhibitor corresponds to empty space of the binding pocket

Subset B. Mode "B" of ligand 24 used as template and modified for further ligands of subset " $B$ " by fixing common moiety. Similarly all structures were aligned on template as shown in Figure 8 and used for CoMFA.

Three different CoMFA models were developed by steric and electrostatic field but the steric field effect based model

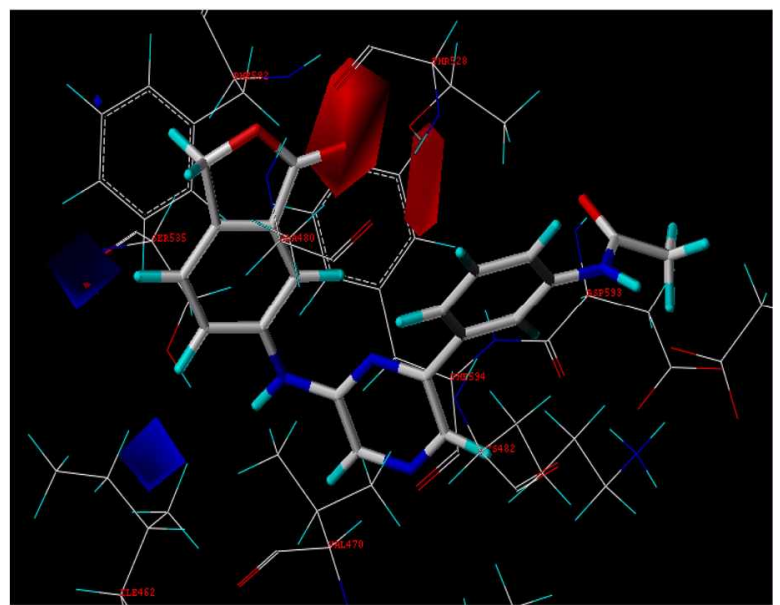

Figure 7. The CoMFA map of subset "A" with electrostatic field effect.

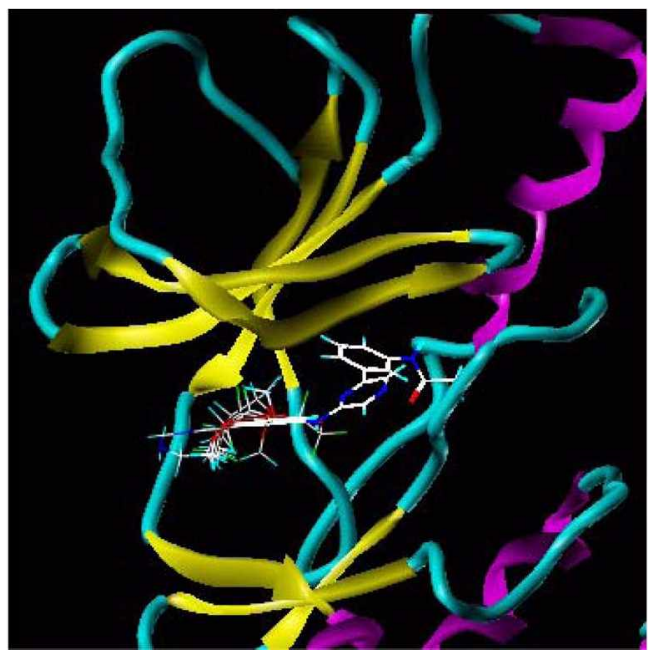

Figure 8. superposition of all molecules of subset B bound to b-Raf.

showed significant relation $\left(q^{2}=0.43, r^{2}=0.74\right)$. This finding also supports the DFT result and reveals the dominance of steric interaction among the ligand of subset " $\mathrm{B}$ ". CoMFA contour map of subset " $\mathrm{B}$ " is shown in Figure 9. A green contour near to oxygen and carbonyl group of furan ring indicates that a bulky group is desirable around this region. This region corresponds to SER535 of receptor protein and holds a hydrogen bond. The indication is reasonable and a

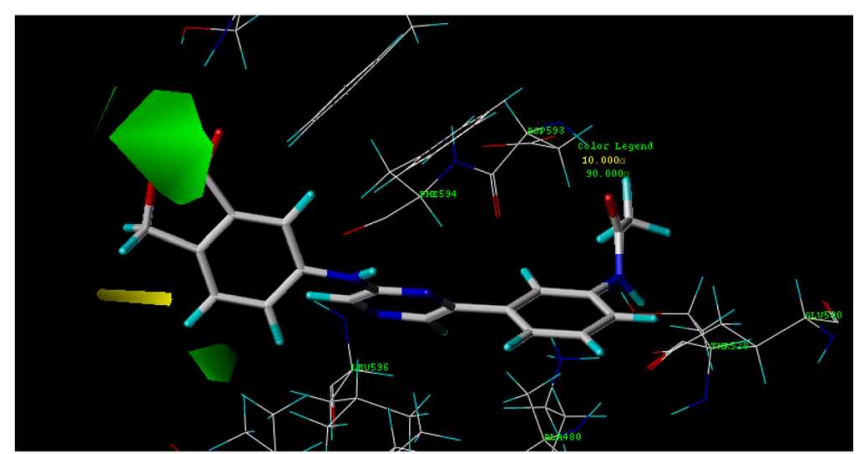

Figure 9. The CoMFA map of subset B by steric field eftect. 
bulky group will give strength to ligand receptor binding. Another green contour also appears around benzene ring adjacent to furan where bulky group at benzene ring will facilitates binding with ILE462 and night be helpful to improve the activity. The yellow isopleth suggests lighter group will be responsible for higher activity of this conpound.

\section{Discussion}

The disubstituted pyrazine derivatives have recently shown vital for b-RAF inhibitory activity but the co-crystal structure of any such ligand is not reported. In the absence of $\mathrm{X}$-ray structure an attempt were made to understand the interaction of ligands with $\mathrm{b}-\mathrm{RAF}$ receptor. The ligand based teclniques such as systematic search and randon search were used to develop the CoMFA models. All the models derived from the ligand based aligiment are not statistically significant enough. The inhibitory activity of a series was correlated by steric and electrostatic field effect in different combination. In order to have a more insight we used the density functional theory based QSAR. After careful mining of data. the whole set was divided into two subsets ( $A$ and B). Different descriptors were applied to correlate with activity and the results indicate the existence of heterogeneity of our dataset. The electrostatic interaction is dominant in subset $\mathrm{A}$ and steric bulk interaction is dominant in subset B. Only with the receptor guided aliginient. we could obtain significant CoMFA models. Further in 3DQSAR the molecular docking studies were performed and two plausible binding modes were identified. On the basis of DFT and molecular docking results. two different CoMFA models were developed. These models can relate the inhibitory activities to binding modes.

\section{Conclusion}

The study reveals that a flexible ligand can have several plausible binding modes at the same receptor protein. The different binding modes may hold different kind of interaction which depends on physicochemical properties of ligands and particular binding pocket. In case of b-RAF inhibitors. two different binding modes $A$ and $B$ were identified with electrostatic and steric interactions respectively. The compounds of subset A favored binding mode "A" and a red contour appear around carbonyl group of benzofuran moiety indicates that an electronegative group is helpful to improve the activity while A blue contour at benzene ring adjacent to furan implies that a electropositive group is desirable. In case of subset " $\mathrm{B}$ " green contour near to oxygen and carbonyl group of furan ring indicate that around this region a bulky group is desirable to improve the activity.

Acknowledgments. This study was supported by research funds from Chosun University. 2008. We thank Mr. Hwan Won Chung for comments

\section{References}

1. Ikawa. S.: Fukui. M.: Ueyama. Y.: Tamaoki. N.: Yamamoto. T:: Toyoshima, K. Mol. Cell Biol. 1988, 8. 2651-2654.

2. Sridhar, S. S.; Hedley. D; Siu, L. L. Mol. Cancer Ther 2005 .4. 677-685.

3. Malumbres. M.: Camero. A. Prog. Cell Cycle Res 2003. 5. 5-18.

4. Davies. H.: Bignell. G. R.: Cox. C.: Stephens. P.: Edkins. S.: Clegg. S.: Teague. J.: Wotfenditl. H.: Garnett. M. J.: Bottomley. W.: Davis. N.; Dicks, E.: Ewing, R; Floy, Y: Gray. K.: Hall, S.: Hawes. R: Hughes. J.; Kosmidou, V: Menzies. A.: Mould. C.: Parker, A.: Stevens, C.: Watt. S.: Hooper. S.: Wilson. R.: Jayatilake, H: Gusterson. B. A.: Cooper. C.: Shipley. J.: Hargrave. D.: PritchardJones. K.: Maitland. N.: Chenevix-Trench. G.: Riggins. G. T.: Bigner. D. D.: Palmieri. G.: Cossu. A.: Flanagan. A.: Nicholson. A.: Ho. J. W.: Leung, S. Y.: Yuen. S. T.: Weber. B. L.; Seigler. H. F; Darrow. T. L: Paterson. H; Marais. R.: Marshall, C. J; Wooster. R: Stratton. M. R; Futreal. P. A. Natwe 2002. 117,949-954.

5. Tuveson1. D. A.: Weber. B. L.: Herlyn. M. Cancer Cell 2003. $t$. 95-98.

6. Niculescu-Duvaz. I.: Roman. E.: Whittaker. S. R.: Friedlos. F.: Kirk. R.: Scanlon, I. J.; Davies. L. C.: Niculeseu-Duvaz, D: Marais, R.: Springer. C. J. J. Med. Chem. 2006, 49, 407-416.

7. Brose. M. S.; Volpe, P.: Feldman, M.: Kumar. M.; Rishi. I.: Gerrero, R.: Einhom. E.: Herlytr. M.: Mint1a. J.: Nicholson. A.: Roth. I. A.: Albelda. S. M.: Davies. H.: Cox. C.: Brignell. G.: Stephens. P.: Futreal. P. A.: Wooster. R.: Stratton. M. R.: Weber. B. L. Cancer Res. 2002. 62.6997.7000

8. Xu. X.: Quiros, R. M.: Gattuso, P.: Ain. K. B.; Prinz. R. A. Cancer Res. 2003, 63,4561-4567.

9. Morrison, D. K. Nature 2004, $428,813-815$

10. Rarey: M.: Kramer. B.: Lenganer. T.: Klebe. G. J. M fol Biol. 1996. $261.470-489$.

11. Lowinger. T. B.: Riedl. B.: Dumas. J.: Smith. R. A. Curr. Phamt. Des. 2002, 8, 2269-2278.

12. Khire. U. R ; Bankston, D.; Barhosa. J.; Brittelli. D. R.; Caringal, Y.: Carlson. R.; Dumas. J.; Gane, T.; Heald, S. L.; Hibner, B.: Johnson1. J. S.: Katz. M. E.: Kenture. N.: Kingery-Wood. J.: Lee. W.: Liu. X. G: Lowinger. I. B.: McAlexander. I.: Monahan. M. K: Natero. R.: Renick. T.: Riedl. B.: Rong. H.: Sibley. R. N.: Smith. R. A.: Wolanin. D. Bioorg. 1/ed. Chem. Lett. 2004, 1t, $783-786$.

13. Lackey, K: Cory, M.: Davis. R.; Frye S. V.; Harris, P. A.; Hunter. R. N.; Jung, D. K.; MeDonald, O. B.; MeNutt, R. W.: Peel, M. R: Ruthowske. R. D.: Veal. J. M.: Wood. E. R. Bioorg. Hed Chent. Lett. 2000. 10. 223-226

14. Hall-Tackson. C. A.: Eyers. P. A.: Cohen. P.: Goedert. M.: Boyle. F. T.; Hewitt. N.: Plant. H.; Hedge, P. Chem. Biol 1999, 6. 559-568

15. Thaimattam, R; Daga, P; Rajjak. S. A; Banerjee. R.: Iqbal, J Bioorg. 1 led Chem. 2004, 12.6415-6425.

16. Pasha. F. A.: Srivastava. H. K.: Singh. P. P. Bioong Med Chen. 2005. 13. 6823-6829.

17. Pasha. F. A.: Srivastava. H. K.: Singh. P. P. Mol. Divers 2005. 9. $215-220$.

18. Ashek, A.: Cho. S. J. Bioorg. Med Chem 2006. 14. 1474-1482

19. (a) Ashek. A.: Lee. C.: Park, H. Cho, S. J. Chemosphere 2006. 65. 521-529. (b) Pasha. F. A.: Muddassar. M.: Jung. H.: Yang. B.S.: Lee. C.: Oh. T. S.: Cho. S. I.: Cho. H. Bull Korem Chent. Soc. 2008. 29(3). 647. (c) San Tuan. A. A.: Cho. S. J.: Cho. H. Bull. Korean Chem. Soc. 2006. 27(10), 1531.

20. Clark, M.: Cramer. R. D.: Vanopdenbosch. N. Joumal of Computational Chemistry 1989. 10,982-1012.

21. Cramer. R. D.: Patterson. D. E.: Bunce. T. D. J. Am. Chem. Soc 1988. $110.5959-5967$.

22. Parr. R. G.: Pearsont. R. G. J. Am. Chent. Soc. 1983. 105. 7512-7516.

23. Iczkowski. R.; Margrave, J. L. J. Am. Chem. Soc 1961. 83. $3547-3549$

24. Parr. R. G; Von Szentpaly. L.; Liu. S. B. J. Am. Chem. Soc. 1999. 121. 1922-1924 